\title{
Los conceptos de novela e historia en El Paraíso en la otra esquina (con una coda a propósito de El sueño del celta)
}

\author{
Fernando RoDRÍGUEZ MANSILLA \\ Spanish and Hispanic Studies Department \\ Hobart and William Smith Colleges
}

\begin{abstract}
RESUMEN
Este artículo se propone analizar El Paraíso en la otra esquina (2003) a partir de la oposición de los conceptos de "novela" e "historia", los cuales forman parte esencial de la poética narrativa de Mario Vargas Llosa. Dichos conceptos operan como pivotes para la caracterización de la pareja protagónica: Flora Tristán y Paul Gauguin. Las trayectorias vitales de estos personajes, distantes no solo en años, sino sobre todo en metas, se delinean como dicotómicas, tal como se oponen la novela y la historia dentro del marco teórico sobre el género novelesco que maneja el autor. Las fluctuaciones entre verdad/mentira e historia/novela se mezclan con posturas y metas de vida que se plantean Flora Tristán y Paul Gauguin. Más allá de los personajes de El Paraíso en la otra esquina, ciertos rasgos de Roger Casement, protagonista de El sueño del celta (2010) nos llevan a comprender a este personaje como una fusión de las actitudes vitales representadas por Flora Tristán y Paul Gauguin.
\end{abstract}

Palabras clave: Vargas Llosa, novela, historia, paraíso, celta.

The Concepts of Novel and History in El Paraíso en la otra esquina (with a coda about El sueño del celta)

\begin{abstract}
This article analyzes the novel El Paraíso en la otra esquina (2003) by discussing the dichotomy of the terms "novel" and "history". These concepts are essential to the novelistic theory forged by Mario Vargas Llosa. Moreover, these pivotal ideas determine the characterization of the novel's two protagonists: Flora Tristán and Paul Gauguin. Their paths seem to be totally opposite, just like "novel and "history" do in Vargas Llosa's theoretical framework. The fluctuations between true/lie and history/novel are figured as crossroads, just like Tristán's and Gauguin's opinions and goals. Beyond the characters' construction in El Paraíso en la otra esquina, the protagonist of Vargas Llosa's new work El sueño del celta, Roger Casement, appears to be the fusion of both vital vocations represented by Flora Tristán and Paul Gauguin.
\end{abstract}


Key words: Vargas Llosa, Novel, History, Paradise, Celt.

SUMARIO: 1. Los conceptos de "novela" e "historia". 2. Flora Tristán y Paul Gauguin en El Paraíso en la otra esquina. 3. Coda a propósito de El sueño del celta.

\section{Los conceptos de "novela" e "historia"}

Desde la antigüedad, la literatura y la historia han sido consideradas discursos opuestos. En el tercer capítulo de la segunda parte de Don Quijote de la Mancha, el ingenioso hidalgo apela a esta postura en su primera conversación con el bachiller Sansón Carrasco. Cuando este le comenta que en el libro de Cide Hamete se cuentan en detalle los reveses sufridos por la pareja protagonista, don Quijote, considerando la calidad literaria del texto, defiende el que el poeta "calle por equidad" y no perjudique el valor del protagonista pues "a fee que no fue tan piadoso Eneas como Virgilio le pinta, ni tan prudente Ulises como le escribe Homero" (Cervantes 1982: 599). Esta afirmación de don Quijote es avalada por el bachiller, quien sintetiza muy bien la preceptiva clásica proveniente de Aristóteles:

Así es -replicó Sansón-; pero uno es escribir como poeta y otro como historiador: el poeta puede contar o cantar las cosas, no como fueron, sino como debían ser; y el historiador las ha de escribir no como debían ser, sino como fueron, sin añadir ni quitar a la verdad cosa alguna. (Cervantes 1982: 599-600)

La historia se ocupa de la verdad particular, "sin añadir ni quitar" nada; la literatura, al representar los sucesos "como debían ser", aspira a reflejar la verdad universal ${ }^{1}$. Mientras el Ulises histórico es un individuo como cualquier otro, un partícipe más de la guerra de Troya, el Ulises literario se ofrece como modelo de ingenio, como un ejemplo para el resto de los hombres. Mientras el primero no trasciende, pues se queda en lo particular, el segundo encarna valores, significados, y en ese sentido es antihistórico. Vista así, la naturaleza de la literatura está basada en una dicotomía que entraña diferenciar entre lo real, sin censuras ni añadidos, y lo imitado, lo artificialmente recreado, o sea, lo falso. Dado que la literatura es considerada una representación, o sea algo que remeda lo real, aparece una constante necesidad de justificarla (Sontag 1966: 3-4), de la cual se extrae, casi siempre, un propósito moral (de acuerdo con la preceptiva horaciana: prodesse et delectare) o uno de reflexión existencial (en términos filosóficos, políticos,

${ }^{1}$ Esta oposición entre textos ficcionales e históricos que se encuentra en la Poética aristotélica, fundamental en la teoría literaria, permite delimitar la naturaleza de diversas modalidades ficcionales (Reisz 1986: 146-148). 
económicos, sociales, etc.), tal y como nos han acostumbrado los escritores del romanticismo en adelante.

En su libro de ensayos La verdad de las mentiras, Mario Vargas Llosa sostiene algo similar: las novelas son "mentirosas" (según criterios de la historia, a la caza de verdades individuales), pero en su mentira encierran una verdad (la verdad universal, diría Aristóteles). En uno de los pasajes más reveladores del ensayo homónimo que abre el volumen se señala:

Los hombres no viven solo de verdades, también les hacen falta las mentiras: las que inventan libremente, no las que les imponen; las que se presentan como lo que son, no las contrabandeadas con el ropaje de la historia. La ficción enriquece su existencia, la completa, y transitoriamente, los compensa de esa trágica condición que es la nuestra: la de desear y soñar siempre más de lo que podemos realmente alcanzar. (Vargas Llosa 1993: 17)

Desde el punto de vista vargasllosiano, la literatura, particularmente la novela, se concibe como un acto de rebeldía frente al mundo. La insatisfacción genera la literatura, a causa de la inclinación del ser humano por crear mundos alternativos: "El novelista distorsiona la realidad a partir de sus obsesiones y creencias produciendo en su obra una realidad ficticia que es- en relación a la realidad realuna mentira, ya que transforma la vida vivida con palabras y sustituyendo el tiempo real con el de la ficción" (Sobrevilla 2011: 444). La novela, una "mentira" verbal mañosamente urdida, tiene la capacidad de contener una "verdad" para el lector, la de su propia condición humana. La "verdad de las mentiras" es el significado trascendental que subyace a toda buena ficción literaria. El hombre no se conforma con la historia, es decir con lo real: con lo que ocurrió, lo que ocurre y lo que ocurrirá. He allí la brecha que genera la novela y el placer que esta produce: "What differentiates a novel from a historical or biographical testimony is the element of fantasy" (Kristal 1998: 28). Ciertamente, la historia también puede incluir mentiras, aunque estas, señala Vargas Llosa, serían "contrabandeadas" o sea filtradas sin el consentimiento del lector, quien posee otros horizontes de lectura al leer un texto histórico.

En el sistema literario vargasllosiano, novela e historia se oponen, en principio, como mentira y verdad, blanco y negro, arriba y abajo ${ }^{2}$. Precisamente, en $E l$ Paraíso en la otra esquina (2003), se pone en discusión estos conceptos,

${ }^{2}$ La concepción de la novela como "mentira verdadera", en oposición a la "verdad" del texto histórico, fue abrazada por Vargas Llosa a partir de 1980 y puesta en práctica por primera vez en Historia de Mayta (1984); a partir de entonces abandonó el ideal previo de la "novela total", cuya última manifestación por entonces fue La guerra del fin del mundo, publicada en 1981 (Sobrevilla 2011: 430-442). 
empleándolos como pivotes para la caracterización de sus dos protagonistas, Flora Tristán y Paul Gauguin. Las trayectorias vitales de estos personajes, distantes no solo en años, sino sobre todo en metas, se delinean como dicotómicas, tal como se oponen la novela y la historia dentro del marco teórico sobre el género novelesco que maneja el autor. Sin embargo, a lo largo de El Paraíso en la otra esquina veremos que la dicotomía se complica y ambos términos se vuelven las dos caras de una misma moneda. La escritura, bajo ciertas circunstancias y con la ya conocida censura del autor al respecto, es la que miente. En este proceso, se hacen evidentes no solo los prejuicios literarios del autor, sino igualmente los ideológicos, ya que en su particular teoría de la novela se entrecruzan la política y el goce estético ${ }^{3}$. Las fluctuaciones entre verdad/mentira e historia/novela se mezclan con posturas y metas de vida que se plantean Flora Tristán y Paul Gauguin.

\section{Flora Tristán y Paul Gauguin en El Paraíso en la otra esquina}

Pasemos ahora a analizar más a fondo a la pareja protagónica de El Paraíso en la otra esquina. Estos personajes vivieron sus años formativos con el hechizo de la mentira cifrada en textos literarios, sin reflexionar por entonces en torno a ello. La diferencia está en cómo resuelven el dilema de la mentira al cotejar lo leído en los libros con la vida real cuando maduran y aspiran a empresas mayores. Especialmente en la exposición de los avatares del personaje de Flora Tristán se dramatizan muy bien todas estas actitudes conflictivas frente al discurso novelesco, mientras que en su nieto Gauguin la disyuntiva tiende a desaparecer, con el apoyo firme de las teorías vargasllosianas, cuya preceptiva parece estar encarnada en el personaje del pintor.

Veamos cómo Flora Tristán tiene que lidiar con el impacto de la novela durante su desarrollo vital. En sus años de juventud, el personaje sigue la corriente de las novelas. Encuentra en ellas un sustento para sus acciones. Así, al inicio de su relación con André Chazal, su violento primer esposo, escribe una carta según la retórica al uso novelesco:

Si lo que sentías por monsieur Chazal era el amor, entonces el amor era una mentira. No tenía nada que ver con el de las novelas, ese sentimiento tan delicado, esa exaltación poética, esos deseos ardientes [...] Y, sin embargo, Florita idiota, Andaluza incauta, después de aquella repugnante violación -fue eso, ¿no?escribiste a André Chazal esa carta que el miserable haría pública diecisiete años más tarde, ante un tribunal de París [...] ¿Por qué se la escribiste si te habías

${ }^{3}$ Un resumen de esta ligazón, desde una inicial simpatía marxista y revolucionaria hacia la visión liberal de los últimos treinta años, que surca su teoría novelesca se encuentra en Sobrevilla 2011. La exposición clásica de dicha teoría, que cubre la primera etapa vargasllosiana (hasta Conversación en la Catedral) se encuentra en Oviedo 1970: 51-62. 
levantado muerta de asco de aquel chaise longue? Porque eso hacían en las novelitas las heroínas desfloradas. (Vargas Llosa 2003: 49)

Como en muchas otras partes de El Paraíso en la otra esquina, en este fragmento el narrador se inscribe en lo que Lubomír Dolezel denomina Subjetivized Er-Form o narrador en tercera persona subjetivado. En esta modalidad, se adopta, en el plano formal, la narración en tercera persona, pero en el nivel semántico se asumen las características del discurso propio de un personaje (Dolezel 1980:16$17)^{4}$. Aunque en tercera persona, estamos escuchando la voz interna del personaje de Flora. Evidentemente, gracias a la distancia de los años, que le permite reflexionar sobre sus errores pasados, ella encuentra una contradicción de la mímesis literaria en relación con la realidad que se imita: "La vida no es así", nos diría. Esta postura en contra de la mímesis, dada su raíz performativa, deriva en fanatismo, producto de su incapacidad de reconocer la naturaleza falaz de la ficción. Flora ejerce un rechazo sistemático a toda transposición literaria de los hechos:

"Hacer el amor", esa ceremonia delicada, dulce, en la que intervenían el corazón y los sentimientos, la sensibilidad y los instintos, en la que los dos amantes gozaban por igual, era una invención de poetas y novelistas, una fantasía que no legitimaba la pedestre realidad. No entre las mujeres y los hombres en todo caso. (Vargas Llosa 2003: 52-53)

De lo expresado en la cita se extrae la opinión de Flora en materia sexual, radicalmente distinta a la de su nieto, Paul, quien ejerce su sexualidad sin inhibiciones. Como culminación de su desagrado frente a la literatura, Flora opta por considerar "la necesidad de que en la futura Unión Obrera no solo se prohibiera el dinero, también a los poetas, como hizo Platón en su República” (Vargas Llosa 2003: 218). A sabiendas de los ideales estéticos y políticos de Vargas Llosa, hechos explícitos a lo largo de su trayectoria literaria (la literatura como una evasión voluntaria, una exaltación del yo en oposición al mundo real), se hace más que patente una oposición entre creador y criatura:

Los hombres no están contentos con su suerte y casi todos -ricos o pobres, geniales o mediocres, célebres u oscuros- quisieran una vida distinta de la que viven. Para aplacar -tramposamente- ese apetito nacieron las ficciones. Ellas se escriben y se leen para que los seres humanos tengan las vidas que no se resignan

\footnotetext{
${ }^{4}$ Es el modo que adopta Gustave Flaubert, uno de los referentes de Vargas Llosa, en algunos pasajes de Madame Bovary, por ejemplo, cuando el narrador en tercera persona expone haciéndolos suyos los pensamientos negativos y los reproches silenciosos de Emma hacia su marido.
} 
a no tener. En el embrión de toda novela bulle una inconformidad, late un deseo. (Vargas Llosa 1993: 8)

La mentira literaria está, de esa forma, plenamente justificada y se opone a todo intento de uniformizar a los hombres, quienes, sean como fueren (pobres, ricos, geniales, mediocres, felices, desgraciados, etc.), gozarán por igual de las ficciones por la cuota de compensación que estas poseen. Evidentemente, el pensamiento de Flora se encuentra en la otra orilla: los poetas mienten y confunden, aletargan, deforman la realidad, la falsean e impiden que el pueblo tome conciencia de su opresión. Tal es el caso concreto de la viuda con la que se topa Flora en uno de sus recorridos. Nuestra protagonista la arenga para que deje la pasividad que le impone el modelo de "heroína de novela romántica":

Lo suyo no es un problema, es una solución. La viudez la salvó de tener que descubrir la esclavitud que significa el matrimonio para una mujer. No juegue a sentirse una heroína de novela romántica. Siga mi consejo. Regrese a la vida y ocúpese de cosas más generosas que cultivar su dolor. (Vargas Llosa 2003: 95)

Aquel deseo de vivir otras vidas a través de la ficción constituye un problema para quien, como Flora, organiza una cruzada de pretensiones universales en la que tiene que contar con el apoyo -léase la simpatía y la sumisión- general a su proyecto. No es difícil encontrar en la Flora de El Paraíso en la otra esquina aires dictatoriales cuando se refería a la necesidad de que una cúpula partidaria, un comando central, dirigiera los destinos de la masa obrera: "El pueblo era incapaz de salvarse a sí mismo, solo una élite lo lograría" (Vargas Llosa 2003: 18). ¿Qué más lejano a estos ideales que aquel poder subversivo, deseo individual, egoísta búsqueda del placer, que el propio autor ha teorizado respecto de la literatura? Esta abierta oposición entre personaje y la preceptiva novelesca de su creador puede explicar, en parte, el tratamiento cargado de ironía que recibe Flora de parte del narrador a lo largo de la novela que nos ocupa. Su proyecto político, el comunismo utópico, acaba por ser una quimera más de la ilusa "Florita", con degradador diminutivo constantemente empleado en el relato, que recorre Francia intentando convencer a los obreros del valor de su causa.

A lo largo de sus viajes, Flora se encuentra con lectores fanáticos, adictos al género novelesco, como la viuda mencionada. Son individuos que viven una suerte de utopía personal, inconformes con la vulgaridad de sus vidas, en total oposición a los planes colectivistas (supresión de ficciones incluida) con los que sueña Madame-La-Colère. ¿No es una utopía en miniatura, acaso, el afán de los jóvenes arequipeños de morir por obedecer a sus lecturas antes que a los ideales republicanos? Y quien nos lo revela es Clemente Althaus, que no es partidario de Flora, sino un mercenario escéptico, un fanático de las balas y los sablazos al que no le importa de qué lado pelear con tal de ganar dinero: 


\begin{abstract}
¿Serían capaces de combatir estos muchachos de buena sociedad que, a simple vista, lucían en el campamento como en una de esas mundanas fiestas en que ocupaban su existencia? Althaus decía que la mitad de ellos, sí, combatirían y se harían matar, pero no por ideales sino para parecerse a los héroes de las novelas francesas; y que, la otra mitad, apenas silbaran las balas, correrían como galgos. (Vargas Llosa 2003: 276-277)
\end{abstract}

El episodio de la batalla de Cangallo, de la cual es testigo Flora, permite establecer una oposición evidente entre historia y novela. La transformación que sufrirán los hechos a manos de los historiadores inescrupulosos -novelistas encubiertos a ojos de Flora- es evaluada en función de mentira o verdad. El desajuste entre lo que Flora ve y lo que se escribirá arroja mentira:

Un caos humano que, luego, los historiadores, para satisfacer el patriotismo nacional, volvían coherentes manifestaciones del idealismo, el valor, la generosidad, los principios, borrando todo lo que hubo en ellas de miedo, estupidez, avidez, egoísmo, crueldad e ignorancia de los más, sacrificados de manera inmisericorde por la ambición, la codicia o el fanatismo de los menos. (Vargas Llosa 2003: 303)

Como escritura, la historia es susceptible de mentir cuando es ejercida por quienes, como los historiadores señalados en la cita, siguen arrebatos patrioteros. El riesgo de que la historia mienta pertenecería -siempre según Vargas Llosa en La verdad de las mentiras- a razones políticas: "En una sociedad cerrada la historia se impregna de ficción, pasa a ser ficción, pues se inventa y reinventa en función de la ortodoxia religiosa o política contemporánea, o, más rústicamente, de acuerdo a los caprichos del dueño del poder" (Vargas Llosa 1993: 16). Ejemplo de esa sociedad cerrada bien podría ser el Perú a los ojos de la paria, quien a poco de llegar descubre que la élite criolla, cuyo emblema en Arequipa es su propio tío don Pío Tristán, sojuzga a las mayorías indígenas, negras y mestizas.

En su faceta de ensayista, Vargas Llosa ha reflexionado sobre la función de la verdad histórica y sostiene que esta "es indispensable e insustituible para saber lo que fuimos y acaso lo que seremos" (Vargas Llosa 1993: 18), proponiendo así una ética sólida para los que ejerzan la historiografía. La preocupación de nuestro autor por hacer un deslinde radical entre novela e historia y situar los límites exactos entre la ficción y la realidad es constante en su obra y encuentra su culminación en el libro que dedicó a la vida y obra de José María Arguedas, La utopía arcaica (1996), una de cuyas tesis centrales es demostrar que el mundo andino representado por el autor de Los ríos profundos es eminentemente imaginario (no obstante basado en recuerdos y vivencias de primera mano) y no se corresponde con un afán estrictamente documental. Como bien ha señalado Carmela Zanelli a este respecto: 
interesado en demostrar que la literatura de Arguedas no es un retrato de la realidad, olvida Vargas Llosa que el realismo, como propuso Roland Barthes, se caracteriza únicamente por un 'efecto de realidad', que emana de ese poderoso agente que es el lenguaje. (1999: 190)

Es más, a estas alturas del debate crítico, se han consolidado teorías historiográficas postestructuralistas, como las de Hayden White y F. R. Ankersmit, para quienes "la forma de las narrativas históricas es idéntica a la que encontramos en la narrativa de ficción" (Estrada 2009: 43). De la teoría de la novela vargasllosiana se desprende un rezago positivista que lo lleva a ponderar, naturalmente, el realismo como la forma más lograda de la ficción, tal como el autor lo ha diseccionado en su célebre estudio sobre Gustave Flaubert (La orgía perpetua).

Prejuicios teóricos aparte, dentro del universo novelesco vargasllosiano la dicotomía entre discurso histórico y novela es eficaz y es el pilar sobre el cual descansa la inadaptación de Flora Tristán a su medio, en la medida en que su compromiso político es de índole histórica y revolucionaria, mientras que en la sociedad el resto de los individuos está cómodamente instalado en un universo donde la ficción se abraza como un juego de evasión. Para el personaje de Flora Tristán, la literatura le está ganando la partida a la historia en sus dos dimensiones, la vivida y la escrita: las novelas están tan bien compuestas que hacen que los lectores las vivan intensamente; la historia, en cambio, no solo es, en su día a día, un reflejo de las injusticias, sino que en su faceta escrita está totalmente desencaminada por la falta de sentido ético de los que la ejercen. La verdad histórica se encuentra viciada en el Perú que Flora conoce:

Era posible que dentro de cien años aquella mojiganga, aquella fiesta de las burlas que fue la batalla de Cangallo, figurara en los libros de historia que leerían los peruanos como una página ejemplar del pasado patrio en el que la heroica Arequipa, defensora del presidente elegido, el general Orbegoso, se batía gallardamente contra las fuerzas sublevadas del general Gamarra que, luego de acciones tan sangrientas como bravas, conseguían derrotarla (para resultar victoriosa días después, mágicamente). Sí, Florita: la historia vivida era un mamarracho cruel, y, la escrita, un laberinto de embelecos patrioteros. (Vargas Llosa 2003: 303-304)

Conviene detenernos siquiera brevemente en esa definición de la historia escrita: "Laberinto de embelecos patrioteros". Esta visión mordaz de la historia refleja bien lo resumido por E. Kristal: "Vargas Llosa has written that historians who try to be objective can only offer imperfect interpretations of reality, but novelists who transform live experiences and distort historical events can give a satisfactory coherence of human events" (1998: 123). En Latinoamérica, en particular, ha sido frecuente la visión de la historia como un caos. Pensemos solo en las desventuras y 
reflexiones del decadente Bolívar de El general en su laberinto de Gabriel García Márquez o las peripecias rocambolescas con el cuerpo de Eva Perón en Santa Evita de Tomás Eloy Martínez. La historia es tan frágil como la literatura, de allí que la novela histórica se imponga la búsqueda de los orígenes en una carrera por superar ese laberinto que es la historia, desplazarla o ponerla en ridículo (Elmore 1997: 39). Este objetivo de la novela histórica empieza por su propio estatuto genérico, el cual encierra una paradoja, ya que el término "novela histórica" encierra una contradicción de conceptos. A saber: si la novela se identifica con lo falaz y la historia con la verdad, una novela histórica es una mentira que, alevosamente, quiere pasar por verdad. O sea que una novela histórica implica para el novelista mentir dos veces. La mentira que ya es la novela se duplica al introducir "verdades" de la historia que se convertirán en falaces vistas en conjunto mediante la selección artística que ejerce el autor sobre la realidad. Se trata, en suma, de una "mentira de la verdad", expresión que nos permite jugar con el concepto vargasllosiano de la "verdad de las mentiras": una falsificación de lo que tenía pretensiones de ser veraz, el discurso histórico. En el episodio de Cangallo nos hallamos ante ese propósito: denunciar el engaño histórico que, como las novelas, nos mantiene conformes y aletargados, dichosos de un pasado tan glorioso pese a ser falso: la mentira de una supuesta "verdad", la historia tal y como ha sido transmitida. Una realidad caótica (aquel "laberinto de embelecos patrioteros" inaprensible en primera instancia) puede ser dispuesta por el lenguaje ordenadamente, a la caza de un sentido final, en la ficción literaria:

Las novelas tienen principio y fin y, aun en las más informes y espasmódicas, la vida adopta un sentido que podemos percibir porque ellas nos ofrecen una perspectiva que la vida verdadera, en la que estamos inmersos, siempre nos niega. Ese orden es invención, un añadido del novelista. (1993: 10)

El "orden" considerado un "añadido" llevado a cabo por el creador de la ficción es producto de la selección artística que el novelista ejerce sobre el material que toma de la realidad (Trueblood 1986: 37-44). Este mismo proceso de selección es el que expone en El Paraíso en la otra esquina las contradicciones profundas del personaje de Flora Tristán, las cuales le restan coherencia a su compromiso ideológico, como el egoísmo y la frivolidad que exhibe en sus monólogos ${ }^{5}$. Otro

${ }^{5}$ Luego de una de sus reflexiones sobre la reforma de la sociedad, el personaje se deja llevar por un egocentrismo de lo más insulso: “Te admiro, Florita', exclamó, entusiasmada. 'Oh, Dios, bastaría que envíes diez mujeres como yo a este mundo para que reine la justicia en la Tierra"' (Vargas Llosa 2003: 404). Súmese a esto la superficialidad de Flora al insistir 
tipo de contradicción más relevante en torno al tema que nos ocupa es que uno de sus modelos de conducta, La Mariscala, se equipara con una figura novelesca; aunque se trata de un personaje histórico, es decir verdadero. Y es comprensible que sea este atractivo novelesco el que impulsa a Flora a la acción:

¿Cuál era la verdadera historia y cuál el mito de la Mariscala? Nunca lo averiguarías, Florita. Ese personaje te fascinó, te encendió la imaginación como nadie antes, y, acaso, la aguerrida imagen de esa mujer que parecía salida de una novela, hizo nacer en ti la decisión y la fuerza interior capaces de transformarte en un ser tan libre y resuelto como entonces solo estaba permitido serlo a un hombre. (Vargas Llosa 2003: 311)

Cree Vargas Llosa que los inquisidores españoles, quienes prohibieron leer novelas en América, fueron los primeros en comprender su naturaleza precisamente al descubrir su carácter de incitadoras de deseo. En esa misma senda, Florita reconoce el poder de la ficción, aunque sea consciente de sus fines perniciosos, y no duda en emplearlo al publicar Méphis. Se trataría por lo visto de una novelapanfleto cuya dudosa calidad literaria es vista como una virtud, pues frente a "la estética que adormecía a la gente en un sueño placentero" antepone "la reforma de la sociedad" (Vargas Llosa 2003: 365). Escribir una novela sería para Flora emplear las armas del enemigo para someterlo. Esto revela igualmente el pleno convencimiento de la protagonista de que su cruzada política es también una cruzada contra la novela y sus efectos nocivos, además de un llamado a vivir plenamente en la historia.

En efecto, si la literatura es denunciada por mentirosa y la historiografía es susceptible de caer en servicio del grupo de poder, existe otra concepción, más positiva, de la historia, como aquello en lo que busca convertirse su utopía social: "El cielo dejaría de ser una abstracción, escaparía de los sermones de los curas y la credulidad de los fieles, y se volvería historia, vida de todos los días y para todos los mortales" (Vargas Llosa 2003: 404; resaltado nuestro). Si la historia se identifica ya no solo como el discurso de la verdad sino como la realidad misma, podríamos afirmar que la condición de individuo histórico en Flora se pone de manifiesto en su participación activa en la sociedad. Mientras la pasividad, aquel vivir como en las novelas, se identifica con una vida muelle, ridícula e irreflexiva (estereotipadamente burguesa), Flora huye de la vida novelesca que impone la literatura y desea para sí y su utopía una vida histórica, real. Su participación en la causa sindicalista, sus encuentros con obreros, sus viajes al interior de Francia y al

con relativa frecuencia en que casi no hay hombre que se le resista y no se enamore en secreto de ella. 
exterior, el contacto que toma con todo tipo de personajes -hasta un joven Marxson maneras de insertarse en la historia. Participar en la sociedad, sacudirla y hasta ser perseguida son labores de quien aspira a ser un ente histórico y no novelesco.

Esta inclinación histórica en desmedro de la novelesca es la gran diferencia de la trayectoria de Flora frente a la de su nieto Paul Gauguin, quien renuncia a participar en su sociedad y se pierde, novelescamente diríase, en su búsqueda del Paraíso en Tahití. En otras palabras: huye de la historia y abraza una vida de novela. Desde sus primeros años de pintor, Gauguin asume el valor de la ficción sin problemas: ¿Qué fue lo más importante de todo aquello [de la temporada en Bretaña]? Los
miserables, Koke. La novela de Ví́ctor Hugo la habían leído todos los pintores
que convivían contigo en la pensión de la viuda Marie-Jeanne Gloanec [...] A ti
no te hizo llorar la aventura de Jean Valjean, pero sí te conmovió, más que todos
los libros que habías leído hasta entonces. Tanto, que, cuando, a solicitud del
Holandés Loco y como anticipo de la próxima cohabitación de ambos en Arles,
intercambiaron sus respectivos retratos, te pintaste metamorfoseado en el héroe
de la novela, Jean Valjean, el antiguo penado convertido en santo por infinita
piedad del obispo monseñor Bienvenu, que lo gana para el bien el día que le
entrega los candelabros que aquel había querido robarle. (Vargas Llosa 2003:
288-289)

Detrás de la metamorfosis pictórica de Paul en Valjean no es difícil hallar el deseo de ser Valjean ${ }^{6}$. Una vida intensa y plena de aventura a la manera novelesca es lo que desea Paul. Y las marchas y contramarchas que da su vida en la búsqueda de ese ideal no hacen más que acrisolar su cruzada personal por la belleza. Al menos Flora Tristán cuando mostraba su admiración por la Mariscala se daba lugar a discutir qué de real y qué de leyenda poseía el personaje. Paul Gauguin se muestra como un sujeto plenamente fantasioso, como otro don Quijote o, más decimonónicamente hablando, víctima del bovarismo. Hasta la idea de ir a Tahití fue alimentada por una novela, por una hermosa mentira donde se figuraba el Paraíso en aquella tierra en medio del Pacífico:

Si algo tenías que agradecerle al Holandés Loco era que él, por primera vez, te abrió el apetito por la Polinesia. Gracias a una novelita que cayó en sus manos y que le encantó: Rarahu o El matrimonio de Loti, de un oficial de la marina mercante francesa, Pierre Loti. Ocurría en Tahití y describía un Paraíso terrenal antes de la caída, con una naturaleza bella y ubérrima y unas gentes libres, sanas, sin prejuicios ni malicia, que se entregaban a la vida y al placer con naturalidad,

\footnotetext{
${ }^{6}$ Recuérdese que la pasión por Los miserables de Víctor Hugo se plasma en Vargas Llosa 2004. Kristal comenta esta fascinación vargallosiana (1998: 121-123).
} 
de manera espontánea, llenas de entusiasmo y vigor primitivos. (Vargas Llosa 2003: 334)

Esto puede llevarnos a pensar que desde el principio, desde el nacimiento de la utopía personal de Gauguin, su asidero real, histórico, no existe y que todo descansa sobre el "sueño placentero" -como diría Flora- de hallar un Paraíso en un lugar exótico, donde el artista puede desatar su creatividad mimetizado con su medio. Para su abuela Flora, en cambio, "la utopía se inicia en la falacia del paraíso, en el recuerdo de don Mariano, el padre, como parte de un pasado que nunca tuvo y un futuro que no existe" (Castillo Uculmana 2011: 252). Compárese a propósito, una reflexión de la abuela del pintor sobre las ilusiones novelescas y la necedad de abrazarse a ellas:

Flora, a modo de despedida, ironizó: era egoísta querer ir a refugiarse en un Edén particular dando la espalda al resto del mundo, y muy ingenuo creer al pie de la letra lo que decía Viaje por Icaria, un libro que no era científico ni filosófico, ¡nada más que una fantasía literaria! ¿Quién, con dos dedos de sensatez en la mollera, iba a tomar una novela como un libro doctrinario y una guía para la revolución? (Vargas Llosa 2003: 181)

Ambos personajes buscan lugares ideales: el Paraíso, el Edén, un mundo sin injusticias y donde se vive en armonía. Paul, siguiendo la fantasía novelesca, parece estar más cerca de la raíz ficcional de su objetivo. En cambio, Flora Tristán cae en el error de perseguir aquel paraíso en la tierra a través del sendero de la historia, que no le depara otra cosa que la realidad más cruda. Si Paul es ingenuo desde la órbita de reflexiones de Flora, en el balance final del universo narrativo de El Paraíso en la otra esquina queda mejor parado, ya que abraza un ideal que conjuga la vida con el arte, que es la negación de la realidad mediante la recreación de la misma, acto que lo moralistas u obcecados como Flora considerarían falaz o simplemente "mentira". En otras palabras, "los sueños de Gauguin, en cambio, son más próximos porque los buscará en un pensamiento individual, aunque más tarde alcancen estos, como los sueño de su abuela, niveles más altos que el personal" (Castillo Uculmana 2011: 253). La lección que se extrae, por el contrario, de las aventuras de Flora Tristán es que no existe nada más necio que querer aferrarse a ideales propios de la fantasía literaria dentro de un mundo que se ausculta por la vía de la historia. La elección de su nieto Paul es elocuente: "exotismo", precisamente, refiere lo ajeno, lo que está afuera, de allí que Gauguin "se salga" de la historia, le dé la espalda. Hasta el último momento de su existencia, Koke se aferra a la fantasía novelesca y "exótica":

- ¿Ha leído usted Salambó, esa novela de Flaubert, pastor? -preguntó.

Vernier dijo que sí, aunque, añadió, no la recordaba muy bien. ¿Una historia pagana, de cartaginenses y bárbaros mercenarios, no? Koke le aseguró que era 
hermosísima. Flaubert había descrito con colores flamígeros todo el vigor, la fuerza vital y la potencia creativa de un pueblo bárbaro. Y recitó la primera frase cuya musicalidad le encantaba: "C'etait à Mégara, faubourg de Carthage, dans les jardins d'Hamilcar”. "El exotismo es vida, ¿verdad, pastor?”. (Vargas Llosa 2003: 479)

Nótese que la valoración de la novela se da en términos pictóricos ("colores flamígeros"), enlazando la práctica literaria con el oficio mismo del personaje. Viene al caso tal vez recordar que la cultura oriental se vuelve una obsesión de los europeos en el siglo XIX y que todo artista -Flaubert incluido, pese a sus achaquesrealizaba apenas podía su ritual viaje a Oriente. Para Gauguin efectivamente "el exotismo es vida": renunciar al mundo occidental regido por la historia, volverse un salvaje (en los planos social, artístico y sexual), es un sueño novelesco que él plasma a través de la pintura. Si el artista, tal como el novelista con las ficciones, crea mundos alternativos a través de sus cuadros, Salambó, así evocada al final de su vida, es un espejo donde la obra de Koke puede verse -salvando inevitablemente las distancias del caso. Salambó "deforma" Cartago, ejerce sobre ese episodio del mundo antiguo una discreta selección artística, siempre en aras de la fantasía: convierte los hechos narrados en una mentira basada en una verdad. Cada cuadro de Gauguin "deforma" Tahití, como lo reconoce aquel hechicero que equipara a Koke con un misionero, es decir como un sujeto trasplantado que no puede aún zafarse de sus prejuicios novelescos occidentales y que precisamente por ello tergiversa el significado de lo que experimenta: "No ves al mahu como un algo natural, sino como a un demonio. En eso te pareces a los misioneros, Koke" (Vargas Llosa 2003: 434). No obstante su fantasía novelesca o más bien gracias a ella, en el balance final de El Paraíso en la otra esquina, el romántico Paul obtiene la consagración póstuma, cuando el narrador refiere irónicamente su muerte en medio de la pobreza para indicar de inmediato, al cierre del capítulo, que décadas después la calidad de sus cuadros sería al fin reconocida y que costarían muchísimo dinero.

Este detalle final de El Paraíso en la otra esquina revela el funcionamiento de la sociedad, así como la complacencia del público frente al arte: la rebeldía artística, la persecución del ensueño novelesco, el escapar de la historia de la mano del talento, acaba por ser, tarde o temprano, uno de los vehículos más seguros para trascenderla y quedar plenamente adscrito a ella. En otras palabras: dentro de El Paraíso en la otra esquina la mejor manera de producir un impacto efectivo en la sociedad es a través de la contribución artística guiada por un impulso novelesco, dado que encierra una mentira que ilumina ciertos aspectos que la verdad no puede. La acción política franca que niega el arte, salvo que este sea dirigido, está condenada al fracaso, ya que no sale de los márgenes de la verdad, que es limitada y, hasta cierto punto, empobrecedora y conformista. En palabras de David Sobrevilla: 
En tanto Flora Tristán desarrolla una utopía política, su nieto Paul Gauguin cultiva una utopía artística. La primera puede llegar a ser socialmente muy destructiva, en tanto la segunda tiene la capacidad de convertirse en individualmente fatal para quien la alienta, pero en cambio es socialmente inocua y contribuye a enriquecer el mundo. (2011: 453)

En ambos casos, el de la sindicalista y el pintor, tratamos con miradas subjetivas de individuos que buscan redimirse a sí mismos frente a la posteridad, el temido juicio de la historia: Flora hace todo para insertarse en ella; Gauguin, en cambio, la repele. Son dos maneras radicales, aunque complementarias, que tiene el individuo de encarar la realidad y hacer su propia historia: una de mayor compromiso histórico, pero condenada al fracaso (Flora), y una de carácter novelesco y que será reconocida (Gauguin). Ambas trayectorias tienen una gran cuota de idealismo e ingenuidad, pero la ingenuidad de base artística posee la indulgencia que le otorga el prestigio del don imaginativo, de la mentira bien urdida.

Entre los personajes de Flora Tristán y Paul Gauguin, tal como quedan retratados en El Paraíso en la otra esquina, se encuentran las grandes fisuras entre la verdad y la mentira, la historia y la novela, que el género de la novela histórica entrevera y se esfuerza por borrar. Como "mentira de la verdad", El Paraíso en la otra esquina representa la disyuntiva entre la revolución social y la de cariz artístico. Situados a contrapelo, sus protagonistas abrazan paradigmas opuestos que condicionan el éxito o el fracaso de las empresas que llevan a cabo. La novela se propone privilegiar el paradigma artístico a despecho del político, vistos ambos como opuestos dado que el segundo se propone negar al primero: Flora no comprende el valor de la mentira, mientras su nieto la convierte en el pilar de su existencia. En suma, el maniqueísmo que se extrae de la lectura de El Paraíso en la otra esquina es tan patente que no cabe sino pensar que uno de los objetivos de la novela es mostrar las limitaciones y las ventajas de dos estilos de vida contrapuestos. Este efecto queda reforzado por el carácter bifaz de la narración y la presencia permanente de los conceptos de historia y novela, casi elevados a la categoría de cosmovisiones, para los personajes.

\section{Coda a propósito de El sueño del celta}

Recientemente, Mario Vargas Llosa ha publicado El sueño del celta. El libro se ocupa de narrar las aventuras de Roger Casement, activista contra los abusos de la colonización en el Congo belga y contra la explotación indiscriminada de los indios del Amazonas durante la fiebre del caucho a inicios del siglo XX. Como irlandés, Casement abrazó la causa independentista de su patria tras su periplo por África y América, por lo cual acabó siendo procesado por traidor al imperio británico, que lo había condecorado por su labor diplomática en pro de los indígenas con el título de caballero.

En sí misma, la azarosa vida de Casement posee ya de antemano un perfil eminentemente novelesco. A esta materia tan atractiva, Vargas Llosa le ha agregado 
una estructura binaria que se ha convertido, en los últimos años, en una de sus marcas registradas, tal como otrora lo fueron el monólogo interior y los vasos comunicantes. Siguiendo el planteamiento narrativo de La fiesta del chivo (2000) o El Paraíso en la otra esquina (2003), en El sueño del celta contamos con dos líneas argumentales: en los capítulos impares se nos refiere el momento actual de Roger, prisionero en Londres, a la espera de un indulto que no llega, recibiendo visitas de los pocos amigos que le quedan y evocando personas que conoció a lo largo de su vida; en los pares, se da cuenta de los principales episodios de su vida entre el Congo, la Amazonia y su campaña por la independencia de Irlanda.

El héroe de El sueño del celta es descrito como un sujeto sin vicios aparentes, cual los disciplinados oficiales Gamboa (La ciudad y los perros) y Pantaleón (Pantaleón y las visitadoras) o el propio Mayta (Historia de Mayta) en su etapa comprometida. No obstante, conforme avanzamos la lectura, descubrimos un rasgo más humano de Roger que lo vuelve muy sugerente por encima del lugar común vargasllosiano advertido en los personajes antes mencionados: su inclinación homosexual, que en algunos momentos de su vida se describe en términos de energía feroz que lo lleva a explorar lugares siniestros a la búsqueda de nuevos amantes transitorios. Este elemento de la personalidad de Roger, así como su reflexión, constante durante el encierro, sobre el fracaso de su vida amorosa, dotan al personaje de un brillo de melancolía ${ }^{7}$. Compensar ese fracaso es lo que, se deduce, lo habría conducido a perseguir empresas de un idealismo sobresaliente, ganándose el mote bien merecido de "Bartolomé de las Casas británico" (Vargas Llosa 2010: 59).

En otras palabras, se trata de un héroe algo ingenuo, romántico y muy conmovedor. Ciertos ingredientes de la vida de Roger Casement presentes en $E l$ sueño del celta, así como su origen europeo, animan a trazar un parangón con $E l$ Paraíso en la otra esquina, como si el protagonista fuera la fusión de las actitudes vitales representadas por Flora Tristán y Paul Gauguin, las cuales eran presentadas como dicotómicas. Casement comparte con Gauguin el carácter intrépido, producto de una fiebre literaria juvenil. Además, la pasión desmedida por los muchachitos que posee el irlandés es equivalente a la que sentía Koke por las jóvenes tahitianas, aunque sin el desenlace feliz que tienen los lances del francés, quien vive

\footnotetext{
${ }^{7}$ No obstante, este perfil de Casement también puede interpretarse con algo más de escepticismo, tal como lo hace Dieter Ingenschay, para quien esta novela "no solo contiene un concepto esencialista de la sexualidad, sino que refuerza también los prejuicios contra las formas de vida homosexual [...] En lugar de las tramas sensuales y llenas de humor de la vida heterosexual en sus novelas eróticas, [Vargas Llosa] ha retratado en El sueño del celta a un homosexual triste, perverso y cohibido" (Ingenschay 2011: 62).
} 
gratamente amancebado ${ }^{8}$. Al mismo tiempo, el protagonista de El sueño del celta comparte la vocación justiciera y finalmente política que poseía el personaje de Florita. Como ella, sufre de achaques que no refrenan su ímpetu de viajar y cumplir con lo que considera un deber. Como le ocurría a Flora, su misión parece a veces infructuosa y tiene por enemigo el desánimo que provoca la más cruda realidad que significan las atrocidades cometidas en el Congo y en el Amazonas.

No obstante, he aquí un cambio sagaz: el intenso tratamiento irónico que recibía Flora en El Paraíso, orientado a denostar su empresa, y que se oponía a la glorificación de Gauguin, se encuentra menguado en el caso de Casement. En todo caso, el autor ha tenido a bien crear un personaje autoconsciente, que reconoce sus yerros y puede ver más allá de estos, aunque no deje de ser víctima de los mismos. Quizás esa sutil ridiculización a la que es sometido Casement, el torpe conspirador, encuentra su remate final en el epílogo de El sueño del celta, cuando el narrador (identificable con el autor implícito Mario Vargas Llosa) se refiere a uno de los pocos monumentos erigidos a la memoria del personaje en Irlanda. Aquella imagen de "la caca blanca de las gaviotas chillonas" que cubre el obelisco en homenaje a Casement no deja de ser degradadora y dota de discreta ironía el panegírico que cierra la novela. En ese aspecto, más subyugante todavía se presenta la breve trayectoria de agitador político de Roger, colmada básicamente de buenas intenciones y ningún tipo de destreza para sobrevivir en ello:

Los ocho meses siguientes, Roger tuvo la sensación de que no hacía otra cosa que subir y bajar de los estrados pronunciando arengas. Solo al principio las leyó, luego improvisaba a partir de una pequeña guía. Recorrió Irlanda en todas direcciones, asistió a reuniones, encuentros, discusiones, mesas redondas, a veces públicas, a veces secretas, discutiendo, alegando, proponiendo, refutando, a lo largo de horas y horas, renunciando para ello a menudo a las comidas y al sueño. Esta entrega total a la acción política a veces lo entusiasmaba y, a veces, le producía un abatimiento profundo. (Vargas Llosa 2010: 308)

La evocación del desalentado Casement no deja de guardar semejanzas con el pasado político del propio Vargas Llosa. ¿No suena acaso similar el párrafo sobre la

${ }^{8}$ Este detalle no debe ser pasado por alto: en el universo vargasllosiano el sexo tiene, tal como la ficción, un valor liberador, de válvula de escape, para la creatividad y la fantasía, ya que se impone la concepción hedonista del amor como deleite físico y estético (testimonio de ello es el binomio erótico conformado por Elogio de la madrastra y Los cuadernos de don Rigoberto). Por ello, algún tipo de represión en el aspecto sexual aparece como negativa en un personaje vargasllosiano; de allí que el asco que muestra Flora Tristán en asuntos venéreos derive en una tacha, con contraste con la fogosidad de Paul Gauguin. 
faceta política de Casement que acabamos de citar a las memorias de la campaña electoral de El pez en el agua?

Escribí solo tres discursos, fuera de este, pero improvisé y dije centenares. Durante las giras por el interior y por los barrios de Lima hablaba varias veces, mañana y tarde, y en las últimas semanas el ritmo era de tres o cuatro mítines al día. [...] Traté de usar los estrados para promover ideas y divulgar el programa del frente, evitando la demagogia y el cliché [...] Pero no tuve éxito en ninguna de las dos cosas [...] En los dos últimos meses de campaña para la segunda vuelta intenté resumir nuestra propuesta en unas cuantas ideas, que repetí, una y otra vez, de la manera más simple y directa, envueltas en una imaginería popular. (1996: 191-193)

Hay que reconocerlo: la faceta política de Roger es tan cándida y entusiasta como la del propio novelista hace poco más de veinte años. No sería de extrañar que, siguiendo la vieja teoría de los demonios vargasllosianos, El sueño del celta sea una especie de exorcismo de la participación misma del autor, también ilusa y fracasada, en el terreno político. Finalmente, si con algo logró trascender e influir Roger Casement eficazmente fue con sus escritos, dando fe de que las obras de la pluma pueden ser más contundentes que las de la plaza o la oficina públicas. De ser así, se trataría de una forma más honesta y directa de hacer un ajuste de cuentas con este "demonio" biográfico que la ejercida en El Paraíso en la otra esquina, consistente, básicamente, en zaherir a Flora Tristán, con la cual, de paso, se zahería a las posturas ideológicas opuestas a las del autor. Vargas Llosa intentaría entonces cerrar su propio expediente político, otorgándonos en el Roger Casement de $E l$ sueño del celta un personaje más "redondo" -echando mano de la terminología de E. M. Forster en el clásico Aspects of the Novel (1954: 67-78) que los, en contraste, dicotómicos y algo "aplanados" de Flora Tristán y Paul Gauguin: una figura compleja, de facetas múltiples, aparentemente contradictorias inclusive, que supera de esa forma el divorcio entre la intervención pública, de aspiraciones históricas, y la llamada de la aventura en tierras exóticas, de aliento novelesco, que había plasmado en El Paraíso en la otra esquina. Finalmente, lo que en esta última es antítesis, en El sueño del celta es una síntesis de elementos bien trabados en una trama narrativa amena, con destellos de gran intensidad y un discreto manejo del drama. Los perfiles de Flora Tristán y Paul Gauguin serían como ríos que confluyen en uno nuevo, de mayor factura literaria, cuya corriente refleja la energía creativa y la plena vigencia, al margen de las ideologías, de una obra narrativa, como la de Vargas Llosa, forjada a lo largo de cuarenta años. 


\section{BIBLIOGRAFÍA}

Castillo Uculmana, Patricia.

2011 "Las utopías en El Paraíso en la otra esquina. Acercamiento a Flora Tristán y Paul Gauguin", en Mario Vargas Llosa y la crítica peruana. Lima: Universidad Ricardo Palma/ Editorial Universitaria, pp. 249-256.

Cervantes, Miguel de.

1982 Don Quijote de la Mancha, II. Edc. Martín de Riquer. Barcelona: Planeta.

DOLEZEL, Lubomír.

1980 "Truth and Authenticity in Narrative", Poetics Today, vol. I, núm. 3 , pp. 7-25.

ELMORE, Peter.

1997 La fábrica de la memoria. La crisis de la representación en la novela histórica latinoamericana. México- Lima: Fondo de Cultura Económica.

ESTRADA, Oswaldo.

2009 La imaginación novelesca. Bernal Díaz entre géneros y épocas. Madrid-Frankfurt Am Main: Iberoamericana-Vervuert.

FORSTER, E. M.

1954 Aspects of the Novel. New York, Harcourt: Brace and Company. INGENSCHAY, Dieter.

2011 "Mario Vargas Llosa y el 'pecado nefando", Revista chilena de literatura, vol. 180, pp. 51-63.

KRISTAL, Efraín.

1954 Temptation of the Word. The Novels of Mario Vargas Llosa. Nashville: Vanderbilt University Press.

OVIEDO, José Miguel.

1970 Mario Vargas Llosa. La invención de una realidad. Barcelona: Barral.

REISZ, Susana.

1986 Teoría literaria. Una propuesta. Lima: Pontificia Universidad Católica del Perú.

SOBREVILLA, David.

2011 "Las concepciones novelísticas de Mario Vargas Llosa", en Mario Vargas Llosa y la crítica peruana. Lima: Universidad Ricardo Palma/ Editorial Universitaria, pp. 400-456.

SONTAG, Susan.

1966 "Against Interpretation", en Against Interpretation and Other Essays. New York, Farrar: Straus \& Giroux, pp. 3-14. 
TRUeBloOd, Alan S.

1986 "Sobre la selección artística en el Quijote: 'Lo que ha dejado de escribir' (II, 44)", en Letters and Spirit in Hispanic Writers. Renaissance to Civil War. Selected Essays. Londres: Támesis, pp. 37-44.

VARGAS LLOSA, Mario.

1993 El pez en el agua. Barcelona: Seix Barral.

1996 La verdad de las mentiras. Lima: Peisa.

2003 El Paraíso en la otra esquina. Madrid: Alfaguara.

2004 La tentación de lo imposible. Madrid: Alfaguara.

2010 El sueño del celta. Madrid: Alfaguara.

ZANELLI, Carmela

1999 "Mario Vargas Llosa. La utopía arcaica: José María Arguedas y las ficciones del indigenismo", Lexis, vol. 23, núm. 1, pp. 189-196. 